\title{
COVID-19-Related Economic Anxiety Is As High as Health Anxiety: Findings from the USA, the UK, and Israel
}

\author{
Liad Bareket-Bojmel ${ }^{1}$ (D) $\cdot$ Golan Shahar $^{2} \cdot$ Malka Margalit $^{1,3}$ \\ Published online: 29 May 2020 \\ (C) Springer Nature Switzerland AG 2020
}

\begin{abstract}
As the COVID-19 outbreak peaks, millions of individuals are losing their income, and economic anxiety is felt worldwide. In three different countries (the USA, the UK, and Israel: $N=1200$ ), the present study addresses four different sources of anxiety: healthrelated anxiety, economic-related anxiety, daily routine-change anxiety, and anxiety generated by social isolation. We hypothesized that, economic anxiety would have a similar or greater effect, compared to health anxiety. Results show that in all three countries, the levels of economic and health anxiety were essentially equal, and both surpassed routine-change and isolation anxiety. Although the COVID-19 crisis originated in the health field, this study emphasizes the need to move from a generalized concept of anxiety to specific types of distress, most notably economic anxiety. Economic anxiety results in serious mental and physical health problems and should be attended to by clinical professionals and by policy makers.
\end{abstract}

Keywords COVID-19 • Economic-anxiety · Financial-anxiety · Health-anxiety · State-anxiety

The COVID-19 outbreak is by far the biggest global crisis that has plagued humanity in recent decades. Although the source of the crisis is health-related (https:/www.who.int/), its effects on individuals are numerous: economical, educational, familial, and mental.

Electronic supplementary material The online version of this article (https://doi.org/10.1007/s41811-02000078-3) contains supplementary material, which is available to authorized users.

Liad Bareket-Bojmel

liad@pac.ac.il

1 School of Behavioral Sciences, Peres Academic Center, 10 shimon Peres St, 7610202 Rehovot, Israel

2 Department of Psychology, Ben-Gurion University of the Negev, Beer-Sheva, Israel

3 Tel-Aviv University, Tel-Aviv, Israel 
In this article, we aim to assess the level of state, or situational anxiety (as opposed to trait anxiety), which reflects responses to the changing reality during the COVID-19 outbreak. Earlier surveys focused their attention on various mental health complaints in different countries, calling attention to global anxiety reactions (Kang et al. 2020; Shigemura et al. 2020; Torales et al. 2020). Recognizing that levels of situational anxiety are dependent upon stressful situations (Bradley 2016; Endler and Kocovski 2001; Folkman and Lazarus 1985; Raffety et al. 1997; Spielberger et al. 1970), we explored different types of state anxiety in three different countries during the COVID-19 crisis - the USA, the UK, and Israel-in April 2020, a peak time in the outbreak.

We postulated that, although the source of current crisis is health-related and, hence, should result in health-related anxiety, there are additional sources of anxiety that may have a similar or greater effect. Specifically, we focused on the monetarist threat for the stability and security of personal finances. Literature on financial threat asserts that people are fearful and highly stressed during economic downturns, with young people being disproportionately affected (Fiksenbaum et al. 2017; Marjanovic et al. 2013).

According to the American Psychology Associations 'stress in America report', economy is a major stressor among Americans (APA 2019). Financial stress has influence on psychological distress which was found to then impact different areas of life, for example social relationships (Ferraro and $\mathrm{Su} 1999$ ) family relationships (Prawitz et al. 2013), and researchers also established the relation between financial stress and health (O'Neill et al. 2006; Hanratty et al. 2007). For that reason, it is highly important to identify and treat economic anxiety. Although economic anxiety is often caused by a given external reality, such as an economic crisis in the market, proper treatment will prevent a psychological strain and improve resilience and coping.

We focused on the following four sources of anxiety during the COVID-19 crisis: health-related anxiety, economic-related anxiety, daily routine-change anxiety, and anxiety generated by social isolation. Specifically, we hypothesized that, across all three countries, economic anxiety would have a similar or greater effect, compared to health anxiety.

We also expected that the level of general state anxiety in each of the countries would reflect the objective status of the virus's spread and the level of disruption to individuals' employability and course of life. At the time of measurement, the country with the highest number of confirmed cases and deaths was the USA. (According to the World Health Organization COVID-19 Dashboard [https://covid19.who.int/], in the USA, there were 395,000 confirmed cases of COVID-19, with 12,740 deaths, at the time of measurement.) The UK was also experiencing a major outbreak, especially in terms of the high death rate from the number of confirmed cases $(60,737$ confirmed cases of COVID-19, with 7097 deaths in the UK, at that time). In Israel, the outbreak spread more slowly (9404 confirmed cases of COVID-19, with 71 deaths in Israel at the time of measurement), but the restrictions on residents were similar to those in the UK and USA.

Thus, state anxiety should be higher in the UK/USA, compared with Israel. Finally, in light of the stressful effect of quarantine (Brooks et al. 2020), we expected that, across all countries, quarantined individuals will report higher levels of anxiety. 


\section{Methods}

\section{Participants and Procedure}

One thousand and two hundred participants were sampled through a convenience sample, with 400 participants in each country: the USA (170 males and 230 females, age ranged between 18 and 75 years, $\left.M_{\text {age }}=33.68, \mathrm{SD}_{\text {age }}=10.72\right)$, the UK (198 males, 200 females, and 2 missing, age ranged between 18 and 76 years, $M_{\text {age }}=34.27$, $\mathrm{SD}_{\text {age }}=11.76$ ), and Israel (92 males and 308 females, age ranged between 18 and 79 years, $M_{\text {age }}=40.92, \mathrm{SD}_{\text {age }}=14.13$ ).

In the USA and UK, participants were gathered through a prolific panel (online participant recruitment platform) for monetary compensation. In Israel, participants were gathered through social networks on a voluntary basis. Participants in Israel completed a Hebrew version of the questionnaire which was translated and backtranslated.

\section{Measures}

COVID-19 State Anxiety Sources State anxiety related to the COVID-19 outbreak was measured by the three anxiety-present items (\#3, 6, and 17) of the 6-item short-form taken from the state scale of the Spielberger State-Trait Anxiety Inventory (STAI): "I am tense", "I feel upset", and "I am worried" (Marteau and Bekker 1992). The items were modified to match the following four anxiety sources: health, economic, routinechange, and isolation. For example, the item "I am tense" was modified to the following four items: "I am tense about the possibility of getting sick or that I already was sick with Corona" (health state anxiety); "I am tense about my economic situation" (economic state anxiety); "I am tense by the fact that my routine has changed" (routine-change state anxiety); and "I am tense about my loneliness" (isolation state anxiety).

The other two state anxiety-present items ("I feel upset" and "I am worried") were adjusted accordingly, to create a scale consisting of four subscales of state sources of anxiety (health, economic, routine-change, and isolation), with three items in each subscale (for a total of 12 items). All four of the subscales demonstrated good internal reliability (health $\alpha=.91$; economic $\alpha=.94$; routine-change $\alpha=.93$; isolation $\alpha=.96$ ). The items were presented on a 7-point Likert scale. See Appendix A, in the online supplementary material.

General State Anxiety General level of state anxiety was measured by the following single item: "Most people feel anxious these days. How much do you feel anxious these days?" Participants responded to this item on a 7-point Likert scale, ranging from 1 (not at all) to 7 (very much so).

General Questions Participants also reported on age, gender, and whether, at the time of their participation, they were quarantined. 


\section{Results}

Table 1 presents descriptive statistics, including correlations between variables, means, and standard deviations. First, we expected that general state anxiety levels would match the virus's spread by country. In that sense, it was expected that, in countries with high numbers of confirmed COVID-19 cases or an increased death rate, the level of state anxiety would be higher. On the day that we finalized data collection (9 April 2020), according to the World Health Organization statistics dashboard (https://who. sprinklr.com/), the USA had the highest number of confirmed cases, and, in the UK, the death rate per confirmed cases was high. Thus, we expected that the state anxiety rate in the USA and the UK would be higher, compared to Israel.

To examine this hypothesis, we employed a contrast analysis in the context of a General Linear Modeling (GLM) analysis, where the outcome was General State Anxiety and the predictors were country, gender, age, and quarantine. We compared, on an a priori basis, Israel to the UK and USA $(2,-1,-1)$, and found that this contrast was statistically significant $(F[1,1192]=255.98)$. Israeli participants exhibited lower levels of general anxiety $(M=3.51, \mathrm{SD}=1.61)$, compared to the $\mathrm{UK}(M=5.16$, $\mathrm{SD}=1.35)$ and USA $(M=5.15, \mathrm{SD}=1.41)$. An orthogonal contrast coding comparing the UK to the USA only $(0,1,-1)$ was non-significant $(p=.28)$. In addition to these contrasts, the following predictors evinced a statistically significant effect: gender $(F[1,1192]=36.38$, wherein women were more anxious than men $)$ and being placed in quarantine $(F[1,1192]=9.95$, wherein individuals in quarantine were more anxious than those who were not in quarantine).

Our main hypothesis was that, although the current COVID-19 crisis is clearly a health-related crisis, other sources of state anxiety would emerge in other areas of life affected by this stress: economic, routine-change, and isolation. Specifically, our hypothesis was that economic anxiety would have a similar or greater effect, compared to health anxiety, across all three countries.

Table 1 Correlations among the variables

\begin{tabular}{|c|c|c|c|c|c|c|c|}
\hline Variable & GA & HA & EA & RA & IA & QU & Age \\
\hline GA & & $.619^{* *}$ & $.399 * *$ & $.528 * *$ & $.439 * *$ & $-.271 * *$ & $-.160 * *$ \\
\hline HA & & & $.355^{* *}$ & $.409^{* *}$ & $.310 * *$ & $-.204 * *$ & $-.075^{* *}$ \\
\hline EA & & & & $.487 * *$ & $.368 * *$ & $-.139 * *$ & $-0.156^{* *}$ \\
\hline RA & & & & & $.549 * *$ & $-.199 * *$ & $-.170^{* * *}$ \\
\hline IA & & & & & & $-.215^{* *}$ & $-.175^{* * *}$ \\
\hline QU & & & & & & & $.205^{* * *}$ \\
\hline Mean & 4.61 & 3.94 & 4.02 & 3.71 & 2.78 & - & 36.79 \\
\hline SD & 1.65 & 1.65 & 1.84 & 1.72 & 1.8 & - & 12.71 \\
\hline
\end{tabular}

Notes

$* p<.05, * * p<.01$.

$G A=$ General state anxiety item; $H A=$ Health state anxiety; $E A=$ Economic state anxiety; $R A=$ Routinechange state anxiety; $I A=$ Isolation state anxiety; $Q U=$ Quarantine-yes/no, dummy variable 0 for "yes", 1 for "no" 
To test this hypothesis, we employed a contrast analysis in the context of a Repeated Measure General Linear Modeling (GLM) analysis, where the repeated measure outcome was the four sources of anxiety: health, economic, routine-based, and isolation. Furthermore, the predictors were country, age, gender, general anxiety, and quarantine. We compared, on an a priori basis, health and eeconomic anxiety to routine-change and isolation anxiety $(1,1,-1,-1)$. This contrast was statistically significant $(F[1,1191]=227.39, p<.001)$. As shown in Fig. 1, levels of health and economic anxiety were higher than levels of routine-change and isolation anxiety. An orthogonal contrast comparing economic $(1)$ and health $(-1)$, irrespective of routinebased (0) and isolation (0) anxiety was non-significant $(p=.28)$. In contrast, an orthogonal contrast comparing routine-based (1) vs. isolation $(-1)$, irrespective of health $(0)$ and economic (0) anxiety, yielded a statistically significant effect, favoring routine-change anxiety $(F[1,1191]=267.46, p<.001)$. In addition to these contrasts, the following predictors evinced a statistically significant effect: country $(F[2,1191]=$ $3.71, p<.05$, favoring the UK/USA over Israel) and quarantine $(F[1,1191]=11.23$, $p<.001$; favoring being quarantined). Both age and general anxiety also exhibited an effect, but both were qualified by an interaction with the repeated measure outcome $(F[3,3573]=6.78, p<.001$; and $F[3,3573]=8.93, p<.001$, for age and general anxiety, respectively). As reported in Table 2, inspection of unique associations revealed that age was inversely related to economic anxiety, routine-based anxiety, and isolation anxiety. General anxiety was differentially associated with the four anxiety sources: health, economic, routine-change, and isolation.

\section{Discussion}

We examined the sources of participants' state anxiety, in three different countries - the USA, the UK, and Israel — at the peak of a global crisis: the COVID-19 outbreak. Four sources of state anxiety were examined: health, financial, routine-change, and isolation. The UK and USA were in the midst of experiencing a major outbreak whereas in Israel there was relative control of the outbreak. The impact on the residents, at the individual level, was high in all countries (social restrictions, economic impact, etc.).

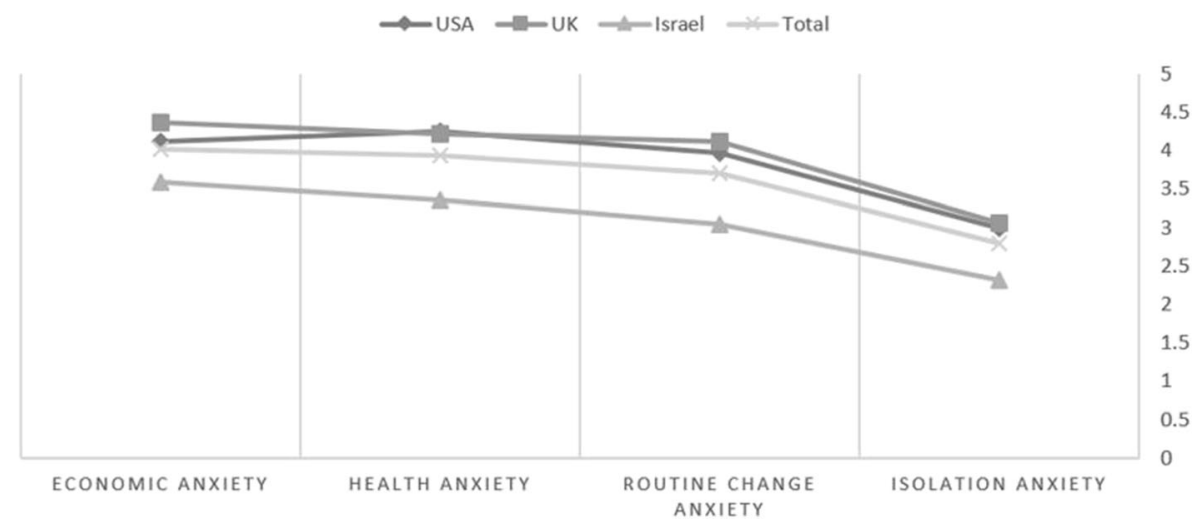

Fig. 1 Economic anxiety is shown to be as high as health anxiety 
Table 2 Age and general anxiety exhibited interaction with the repeated measure outcome

\begin{tabular}{|c|c|c|c|}
\hline & & Age & General anxiety \\
\hline \multirow[t]{5}{*}{ Economic anxiety } & $b$ & -0.01 & 0.44 \\
\hline & S.E. & 0.003 & 0.03 \\
\hline & $t$ & -3.68 & 13.08 \\
\hline & beta & -0.1 & 0.39 \\
\hline & $p<$ & 0.01 & 0.001 \\
\hline \multirow[t]{5}{*}{ Health anxiety } & $b$ & & 0.62 \\
\hline & S.E. & & 0.02 \\
\hline & $t$ & & 24.09 \\
\hline & beta & & 0.62 \\
\hline & $p<$ & & 0.001 \\
\hline \multirow[t]{5}{*}{ Routine change anxiety } & $b$ & -0.01 & 0.52 \\
\hline & S.E. & 0.003 & 0.02 \\
\hline & $t$ & -3.18 & 17.93 \\
\hline & beta & -0.08 & 0.5 \\
\hline & $p<$ & 0.01 & 0.001 \\
\hline \multirow[t]{5}{*}{ Isolation anxiety } & $b$ & -0.01 & 0.47 \\
\hline & S.E. & 0.003 & 0.03 \\
\hline & $t$ & -3.94 & 14.75 \\
\hline & beta & -0.1 & 0.43 \\
\hline & $p<$ & 0.001 & 0.001 \\
\hline
\end{tabular}

We found that the level of general state anxiety corresponded to the epidemic's spread: it was higher in the UK/USA than in Israel. We also found that, in all three countries, the level of economic anxiety was equal in intensity to the level of health anxiety. Thus, although the crisis originated in the health context, our subjects reported high levels of economic anxiety to the same extent. Routine-change and isolation state anxiety, on the other hand, were lower. Finally, as expected (Brooks et al. 2020), quarantine was related to increased general, health, economic, routine-change, and isolation state anxiety.

Economic anxiety is a very serious predicament. As noted above, it is highly prevalent, particularly among younger individuals who are in a developing stage of their lives (Fiksenbaum et al. 2017; Marjanovic et al. 2013). A recent article by Joiner and colleagues highlights the devastating mental health consequences emanating from economic crises related to the shutdown of businesses and workplaces due to the spread of COVID-19 (Reger et al. 2020), predicting a surge of suicidality, subsequent to this crisis. Our findings suggest that this is exactly what the public is experiencing, at least in Israel, the UK, and the USA, countries with very different levels of COVID-19 threat and correspondingly different levels of general situational anxiety. Policy makers are strongly encouraged to consider this severe distress and to attend to the public's 
economic concerns, and clinicians are encouraged to develop specific, evidence-based interventions aimed at alleviating this source of anxiety.

The emerging field of 'financial therapy' stems from the system theory that offers a broad look at the different systems in which the individual operates. Researchers propose to combine clinical and financial consulting with much caution, and to possibly collaborate in the field of economic and psychological counseling to the benefit of the client (Gale et al. 2020).

Financial counseling, or financial therapy, is a relatively new practice which combines therapeutic and financial competencies. Therefore, new therapy methods aimed at both stress and actual financial relief are developed (Britt et al. 2015). Most of these methods focus on behavioral change (Nelson et al. 2015). For example, 'SolutionFocused Financial Therapy' (SFFT) which is a goal focused therapy for financial stress relief (Archuleta and Grable 2010, Archuleta et al. 2020). 'Relational financial therapy' is a collaborative method combining co-therapy of family therapists and financial planners (Kim et al. 2011).

Other methods are utilizing more 'in-depth' approaches offering to change beliefs about money. For example, Klontz and Britt (2012) have identified core beliefs about financial status (called 'money scripts') which are unconscious and usually developed during childhood. By identifying and changing beliefs about money scripts, a change in financial behavior can emerge. Similarly, others offer to identify family patterns related to handling finances and treat the stress and anxiety through narrative therapy related to the emerging financial family patterns (Nelson et al. 2015).

Finally, CBT has been proposed as an effective method of treating maladaptive financial behavior (Nabeshima and Klontz 2015). CBT-based methods partly focus on changing thoughts or beliefs that are self-defeating thoughts and partly focus on providing tools and strategies for coping more effectively with the financial stress. CBT was offered as a treatment for financial hoarding, gambling, compulsive buying etc. (Nabeshima and Klontz 2015). Future research should examine the effectiveness of CBT to treat financial anxiety that is triggered by a stressful financial event such as a financial crisis.

Limitations of this study include the cross-sectional design, which limits causal inference, the exclusive use of causal inference, the exclusive reliance of self-report measures, and an online recruitment which limits generalizability. Note, however, that causality is not at the forefront of our study, that self-report measures are the customary way to assess anxiety, and that online recruitment is increasingly used in research, and is arguably the only possible way to recruit under the outbreak. Study strengths include comparing three countries, examining four sources of COVID-19-related anxiety, and a clear pattern of results. Hopefully, our findings will encourage further research into the potentially devastating consequences of economic anxiety.

\section{Compliance with Ethical Standards}

Conflict of Interest On behalf of all authors, the corresponding author states that there is no conflict of interest. 


\section{References}

American Psychological Association. (2019). Stress in America survey. Washington, DC: APA.

Archuleta, K. L., Mielitz, K. S., Jayne, D., \& Le, V. (2020). Financial goal setting, financial anxiety, and solution-focused financial therapy (SFFT): A quasi-experimental outcome study. Contemporary Family Therapy, 42(1), 68-76.

Bradley, A. (2016). Trait and state anxiety: assessment, predictors and outcomes. Nova Publishers.

Britt, S. L., Archuleta, K. L., \& Klontz, B. T. (2015). Theories, models, and integration in financial therapy. In B. T. Klontz, S. L. Britt, \& K. L. Archuleta (Eds.), Financial therapy: Theory, research, \& practice (pp. 15-22). New York: Springer.

Brooks, S. K., Webster, R. K., Smith, L. E., Woodland, L., Wessely, S., Greenberg, N., \& Rubin, G. J. (2020). The psychological impact of quarantine and how to reduce it: Rapid review of the evidence. The Lancet, 395(10227), 912-920.

Endler, N. S., \& Kocovski, N. L. (2001). State and trait anxiety revisited. Journal of Anxiety Disorders, 15(3), 231-245.

Ferraro, K. F., \& Su, Y. P. (1999). Financial strain, social relations, and psychological distress among older people: A cross-cultural analysis. The Journals of Gerontology Series B: Psychological Sciences and Social Sciences, 54(1), S3-S15.

Fiksenbaum, L., Marjanovic, Z., Greenglass, E., \& Garcia-Santos, F. (2017). Impact of economic hardship and financial threat on suicide ideation and confusion. The Journal of Psychology, 151(5), 477-495.

Folkman, S., \& Lazarus, R. S. (1985). If it changes it must be a process: Study of emotion and coping during three stages of a college examination. Journal of Personality and Social Psychology, 48(1), 150.

Gale, J., Ross, D. B., Thomas, M. G., \& Boe, J. (2020). Considerations, benefits and cautions integrating systems theory with financial therapy. Contemporary Family Therapy, 42(1), 84-94.

Hanratty, B., Holland, P., Jacoby, A., \& Whitehead, M. (2007). Financial stress and strain associated with terminal cancer-A review of the evidence. Palliative Medicine, 21(7), 595-607.

Kang, L., Li, Y., Hu, S., Chen, M., Yang, C., Yang, B. X., et al. (2020). The mental health of medical workers in Wuhan, China dealing with the 2019 novel coronavirus. Lancet Psychiatry, 7(3), e14.

Kim, J. H., Gale, J., Goetz, J., \& Bermúdez, J. M. (2011). Relational financial therapy: An innovative and collaborative treatment approach. Contemporary Family Therapy, 33(3), 229-241.

Klontz, B. T., \& Britt, S. L. (2012). How clients' money scripts predict their financial behaviors. Journal of Financial Planning, 25(11), 33-43.

Marjanovic, Z., Greenglass, E. R., Fiksenbaum, L., \& Bell, C. M. (2013). Psychometric evaluation of the financial threat scale (FTS) in the context of the great recession. Journal of Economic Psychology, 36, 110.

Marteau, T. M., \& Bekker, H. (1992). The development of a six-item short-form of the state scale of the Spielberger state-Trait anxiety inventory (STAI). The British Journal of Clinical Psychology, 31(3), 301-306.

Nabeshima, G., \& Klontz, B. T. (2015). Cognitive-behavioral financial therapy. In Financial Therapy (pp. 143-159). Cham: Springer.

Nelson, R. J., Smith, T. E., Shelton, V. M., \& Richards, K. V. (2015). Three interventions for financial therapy: Fostering an examination of financial behaviors and beliefs. Journal of Financial Therapy, 6(1), 33-43.

O'Neill, B., Prawitz, A., Sorhaindo, B., Kim, J., \& Garman, E. T. (2006). Changes in health, negative financial events, and financial distress/financial well-being for debt management program clients. Journal of Financial Counseling and Planning, 17(2).

Prawitz, A. D., Kalkowski, J. C., \& Cohart, J. (2013). Responses to economic pressure by low-income families: Financial distress and hopefulness. Journal of Family and Economic Issues, 34(1), 29-40.

Raffety, B. D., Smith, R. E., \& Ptacek, J. T. (1997). Facilitating and debilitating trait anxiety, situational anxiety, and coping with an anticipated stressor: A process analysis. Journal of Personality and Social Psychology, 72(4), 892.

Reger, M. A., Stanley, I. H., \& Joiner, T. E. (2020). Suicide mortality and coronavirus disease 2019-A perfect storm? JAMA Psychiatry. 
Shigemura, J., Ursano, R. J., Morganstein, J. C., Kurosawa, M., \& Benedek, D. M. (2020). Public responses to the novel 2019 coronavirus (2019-nCoV) in Japan: Mental health consequences and target populations. Psychiatry and Clinical Neurosciences, 74(4), 281.

Spielberger, C. D., Gorsuch, R. L., \& Luchene, R. E. (1970). State-trait anxiety inventory for adults: Manual and sample: Manual, instrument and scoring guide. Consulting Psychologists Press.

Torales, J., O’Higgins, M., Castaldelli-Maia, J. M., \& Ventriglio, A. (2020). The outbreak of COVID-19 coronavirus and its impact on global mental health. International Journal of Social Psychiatry, 0020764020915212 .

Publisher's Note Springer Nature remains neutral with regard to jurisdictional claims in published maps and institutional affiliations. 